American Journal of Applied Sciences 8 (8): 810-815, 2011

ISSN 1546-9239

(C) 2011 Science Publications

\title{
Adaptive Controllers for Permanent Magnet Brushless DC Motor Drive System using Adaptive-Network-based Fuzzy Interference System
}

\author{
${ }^{1}$ V.M. Varatharaju, ${ }^{2}$ Badrilal Mathur and ${ }^{3}$ Udhayakumar \\ ${ }^{1}$ Department of Electrical Engineering, Anna University, Chennai, 600 025, India \\ ${ }^{2}$ Department of Electrical Engineering, \\ SSN College of Eingineering, Kalavakkam, 603 110, India \\ ${ }^{3}$ Department of Electrical Engineering, Anna University, Chennai, 600025 India
}

\begin{abstract}
Problem statement: The tuning methodology for the parameters of adaptive speed controller causes a transient deviation of the response from the set reference following variation in load torque in a permanent-magnet brushless DC (BLDC) motor drive system. Approach: This study develops a mathematical model of the BLDC drive system, firstly. Secondly, discusses a design of the closed loop drive system employing the Adaptive-Network-based Fuzzy Interference System (ANFIS). The nonlinear simulation model of the BLDC motors drive system with ANFIS control based is simulated in the MATLAB/SIMULINK platform. Results: The necessitated data for training the ANFIS control is generated by simulation of the system with conventional PI controller. Conclusion: The simulated electromagnetic torque and rotor speed signify the superiority of the proposed technique over the classical method.
\end{abstract}

Key words: Adaptive control, PMBLDC motor, speed control, ANFIS

\section{INTRODUCTION}

The Permanent Magnet Synchronous Motor (PMSM) has a sinusoidal back emf and requires sinusoidal stator currents to produce constant torque while the brushless DC (BLDC) motor has a trapezoidal back emf and requires rectangular stator currents to produce constant torque (Varatharaju et al., 2010). The BLDC motor is a permanent-magnet synchronous machine supplied from a six-transistor inverter whose on/off switching is determined by the rotor position (Sing et al 2003; Pillay and Krishnan, 1989).

The complete performance analysis with a design example of an axial field permanent magnet motor servo drive has been discussed (Radwan and Gouda, 2005). A digital speed controller for BLDCM and implemented in a digital signal processor has been proposed (Singh et al., 2003). Vas (1998) has developed the rotor position and the speed of permanent magnet has been estimated by Extended Kalman Filter (EKF). The Hall Effect sensor are usually needed to sense the rotor position which senses the position signal for every 60 degree electrical (Jadric and Terzic, 2001).

The architecture and learning procedure under lying ANFIS (adaptive-network-based fuzzy inference system) have been well discussed. The ANFIS is a fuzyy inference system implemented in the framework of adaptive networks (Kisi, 2005; Huang and Uddin, 2006). ANFIS has been incorporated with two input variables and one control output variable (Uddin et al., 2007).

This study deals with the closed loop modeling of a PMBLDC motor considering the non-linearity in the torque-balance equation and development of an ANFIS controller for improving the transient response following torque disturbances.

\section{MATERIALS AND METHODS}

PMBLDCM drive and modeling: Figure 1 describes the basic building blocks of the PMBLDCM drive. The drive consists of speed controller, reference current generator, PWM current controller, position sensor, the motor and IGBT based Current Controlled Voltage Source Inverter (CC-VSI).

The PMBLDC motor is modeled in the 3-phase abc variables. The general volt-ampere equation for the circuit shown in the Fig. 2 can be expressed as:

$$
\begin{aligned}
& \mathrm{V}_{\mathrm{an}}=\mathrm{Ri}_{\mathrm{a}}+\mathrm{p} \lambda_{\mathrm{a}}+\mathrm{e}_{\mathrm{an}} \\
& \mathrm{V}_{\mathrm{bn}}=\mathrm{Ri}_{\mathrm{b}}+\mathrm{p} \lambda_{\mathrm{b}}+\mathrm{e}_{\mathrm{bn}}
\end{aligned}
$$

Corresponding Author: V.M. Varatharaju, Department of Electrical Engineering, Anna University, Chennai, 600 025, India 
Am. J. Applied Sci., 8 (8): 810-815, 2011

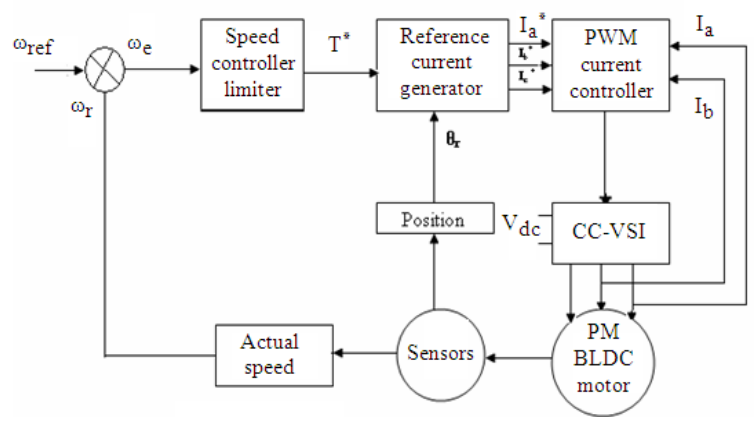

Fig 1: Block Diagram of PMBLDC motor drive

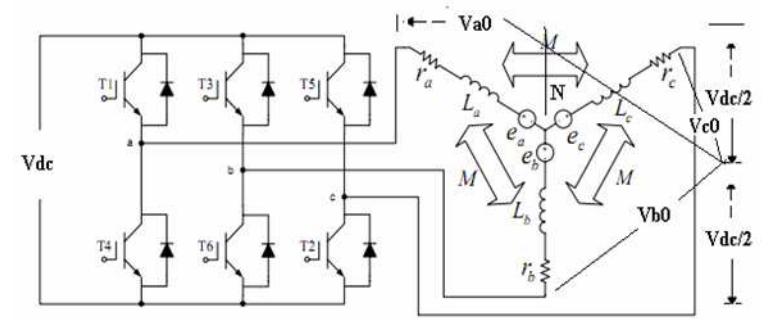

Fig. 2: Inverter and BLDCM equivalent circuit

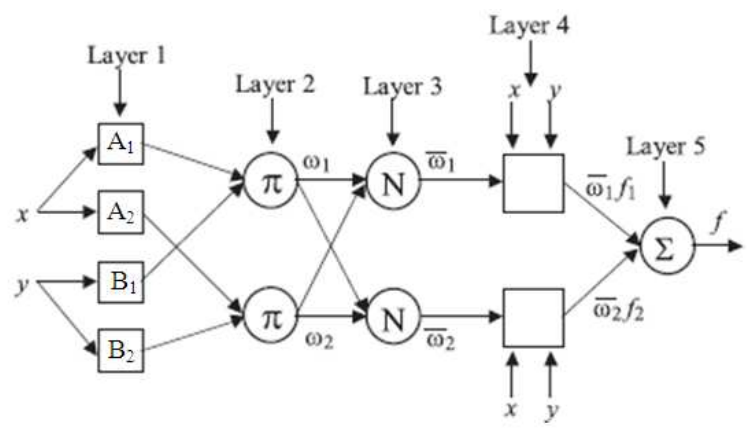

Fig. 3: Adaptive neural network

$\mathrm{V}_{\mathrm{cn}}=\mathrm{R} \mathrm{i}_{\mathrm{c}}+\mathrm{p} \lambda_{\mathrm{c}}+\mathrm{e}_{\mathrm{cn}}$

where, $V_{a n}, V_{b n}$ and $V_{c n}$ are phase voltages and may be defined as:

$\mathrm{V}_{\mathrm{an}}=\mathrm{V}_{\mathrm{ao}}-\mathrm{V}_{\mathrm{no}}, \mathrm{V}_{\mathrm{bn}}=\mathrm{V}_{\mathrm{bo}}-\mathrm{V}_{\mathrm{no}}$ and $\mathrm{V}_{\mathrm{cn}}=\mathrm{V}_{\mathrm{co}}-\mathrm{V}_{\mathrm{no}}$

where, $\mathrm{V}_{\mathrm{ao}}, \mathrm{V}_{\mathrm{bo}}, \mathrm{V}_{\mathrm{co}}$ and vno are three phase and neutral voltages with respect to the zero reference potential at the mid-point of dc link (0) shown in the Fig. 2. R is the resistance per phase of the stator winding, $\mathrm{p}$ is the time differential operator and $\mathrm{e}_{\mathrm{an}}, \mathrm{e}_{\mathrm{bn}}$ and $\mathrm{e}_{\mathrm{cn}}$ are phase to neutral back emfs.

The $\lambda_{\mathrm{a}}, \lambda_{\mathrm{b}}$ and $\lambda_{\mathrm{c}}$ are total flux linkage of phase windings $\mathrm{a}, \mathrm{b}$ and $\mathrm{c}$ respectively. Their values can be expressed as:

$$
\begin{aligned}
& \lambda_{\mathrm{a}}=\mathrm{L}_{\mathrm{s}} \mathrm{i}_{\mathrm{a}}-\mathrm{M}\left(\mathrm{i}_{\mathrm{b}}+\mathrm{i}_{\mathrm{c}}\right) \\
& \lambda_{\mathrm{b}}=\mathrm{L}_{\mathrm{s}} \mathrm{i}_{\mathrm{b}}-\mathrm{M}\left(\mathrm{i}_{\mathrm{a}}+\mathrm{i}_{\mathrm{c}}\right) \\
& \lambda_{\mathrm{c}}=\mathrm{L}_{\mathrm{S}} \mathrm{i}_{\mathrm{c}}-\mathrm{M}\left(\mathrm{i}_{\mathrm{a}}+\mathrm{i}_{\mathrm{b}}\right)
\end{aligned}
$$

where, Ls and M are the self and mutual inductances, respectively.

The PMBLDC motor has no neutral connection and hence this results in:

$\mathrm{i}_{\mathrm{a}}+\mathrm{i}_{\mathrm{b}}+\mathrm{i}_{\mathrm{c}}=0$

Substituting (8) into (5), (6) and (7) the flux linkages are given as:

$\lambda_{\mathrm{a}}=\mathrm{i}_{\mathrm{a}}\left(\mathrm{L}_{\mathrm{s}}+\mathrm{M}\right)$

$\lambda_{\mathrm{b}}=\mathrm{i}_{\mathrm{b}}\left(\mathrm{L}_{\mathrm{s}}+\mathrm{M}\right)$ and

$\lambda_{\mathrm{c}}=\mathrm{i}_{\mathrm{c}}\left(\mathrm{L}_{\mathrm{s}}+\mathrm{M}\right)$

By substituting (9) in volt-ampere Eq. 1-3 and rearranging these equations in a current derivative of state space form, gives:

$$
\begin{aligned}
& \mathrm{pi}_{\mathrm{a}}=\left(\mathrm{V}_{\mathrm{an}}-\mathrm{Ri}_{\mathrm{a}}+\mathrm{e}_{\mathrm{an}}\right) /\left(\mathrm{L}_{\mathrm{s}}+\mathrm{M}\right) \\
& \mathrm{pi}_{\mathrm{b}}=\left(\mathrm{V}_{\mathrm{bn}}-\mathrm{Ri}_{\mathrm{b}}+\mathrm{e}_{\mathrm{bn}}\right) /\left(\mathrm{L}_{\mathrm{s}}+\mathrm{M}\right) \\
& \mathrm{pi}_{\mathrm{c}}=\left(\mathrm{V}_{\mathrm{cn}}-\mathrm{Ri}_{\mathrm{c}}+\mathrm{e}_{\mathrm{cn}}\right) /\left(\mathrm{L}_{\mathrm{s}}+\mathrm{M}\right)
\end{aligned}
$$

The developed electromagnetic torque may be expressed as:

$$
\mathrm{T}_{\mathrm{e}}=\left(\mathrm{e}_{\mathrm{an}} \mathrm{i}_{\mathrm{a}}+\mathrm{e}_{\mathrm{bn}} \mathrm{i}_{\mathrm{b}}+\mathrm{e}_{\mathrm{cn}} \mathrm{i}_{\mathrm{c}}\right) /\left(\omega_{\mathrm{r}}\right)
$$

where, $\omega_{\mathrm{r}}$ is the rotor speed in electrical rad./sec.

ANFIS based control: An adaptive network, as its name implies, is a network structure consisting of nodes and directional links through which the nodes are connected. Moreover, part or all of the nodes are adaptive, which means each output of these nodes depends on the parameter(s) pertaining to this node, and the learning rule specifies how these parameters should be changed to minimize a prescribed error measure. The basic learning rule of adaptive networks is based on the gradient descent and the chain rule.

Fuzzy Logic Control (FLC) is a great tool to deal with complicated, non-linear and ill-defined systems. Artificial Neural Network (ANN) has the powerful 
capability for learning, adaptation, robustness and rapidity. In ANFIS the advantages of both the FLC and ANN have been combined. ANFIS is a class of adaptive networks that is functionally equivalent to fuzzy inference system. This control methodology solves the problem of non-linearity and parameter variations of PMBLDC drive.

ANFIS is designed for PMBLDC motor. The adaptive network, shown in Fig. 3, is a multilayer feed forward network in which each node performs a particular function (node function) on incoming signals as well as a set of parameters pertaining to this node. The formulae for the node function may vary from node to node.

Consider a sugeno type of fuzzy system having the rule base:

- If $x$ is $A_{1}$ and $y$ is $B_{1}$, then $f_{1}=p_{1} x+q_{1} y+r_{1}$

- If $x$ is $A_{2}$ and $y$ is $B_{2}$, then $f_{2}=p_{2} x+q_{2} y+r_{2}$

If the firing strengths of the rules are $\mathrm{w}_{1}$ and $\mathrm{w}_{2}$, respectively, for the particular values of the inputs $A_{i}$ and integral of $\mathrm{B}_{\mathrm{i}}$, then the output computed as weighted average:

$\mathrm{f}=\frac{\mathrm{w}_{1} \mathrm{f}_{1}+\mathrm{w}_{2} \mathrm{f}_{2}}{\mathrm{w}_{1}+\mathrm{w}_{2}}$

Let the membership functions of fuzzy sets $A_{i}, B_{i}$, $\mathrm{i}=1,2$, be $\mu_{\mathrm{Ai}}$ and $\mu_{\mathrm{Bi}}$.

Layer 1: Each neuron " $i$ " in layer 1 is adaptive with a parametric activation function. Its output is the grade of membership function; an example is the generalized bell shape function:

$$
\mu(x)=\frac{1}{1+\left[\frac{x-c}{a}\right]^{2 b}}
$$

where, $[a, b, c]$ is the parameter set. As the values of the parameters change, the shape of the bell-shape function varies.

Layer 2: Every node in layer 2 is a fixed node, whose output is the product of all incoming signals:

$\mathrm{W}_{\mathrm{i}}=\mu_{\mathrm{Ai}}(\mathrm{x}) \mu_{\mathrm{Bi}}(\mathrm{y}), \mathrm{i}=1,2$

Layer 3: This layer normalizes each input with respect to the others (The $\mathrm{i}^{\text {th }}$ node output is the $\mathrm{i}^{\text {th }}$ input divided the sum of all the other inputs):

$$
\overline{\mathrm{w}}_{\mathrm{i}}=\frac{\mathrm{w}_{\mathrm{i}}}{\mathrm{w}_{1}+\mathrm{w}_{2}}
$$

Layer 4: This layer's $i^{\text {th }}$ node output is a linear function of the third layer's $i^{\text {th }}$ node output and the ANFIS input signals:

$\bar{w}_{i} f_{i}=\bar{w}_{i}\left(p_{i} x+q_{i} y+r_{i}\right)$

Layer 5: This layer sums all the incoming signals:

$$
\mathrm{f}=\overline{\mathrm{w}}_{1} \mathrm{f}_{1}+\overline{\mathrm{w}}_{2} \mathrm{f}
$$

\section{RESULTS AND DISCUSSION}

In this work the drive model with PI Speed controller is developed and simulated, first. The set of equations representing the model of the drive system has been discussed. Experimental results are recorded for the same motor using developed SIMULINK model in MATLAB. Figure 4-8 show simulated results. The transient and steady state responses are obtained for a 3 phase, $2.0 \mathrm{hp}$, 4- pole $1500 \mathrm{rpm}, 4 \mathrm{~A}$, motor (Detailed motor specifications are given in appendix).

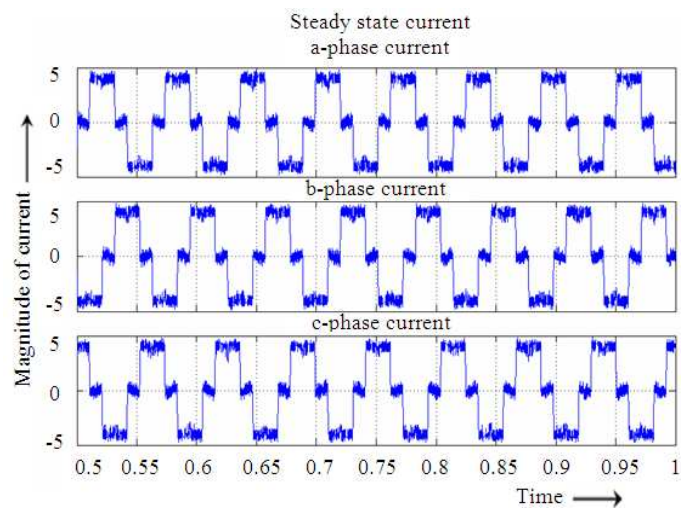

Fig. 4: Stator current of BLDC motor

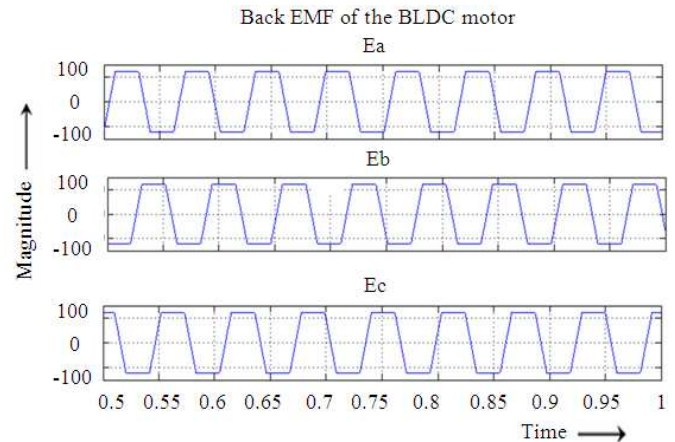

Fig. 5: Represents the Trapezoidal back EMF of BLDC motor 


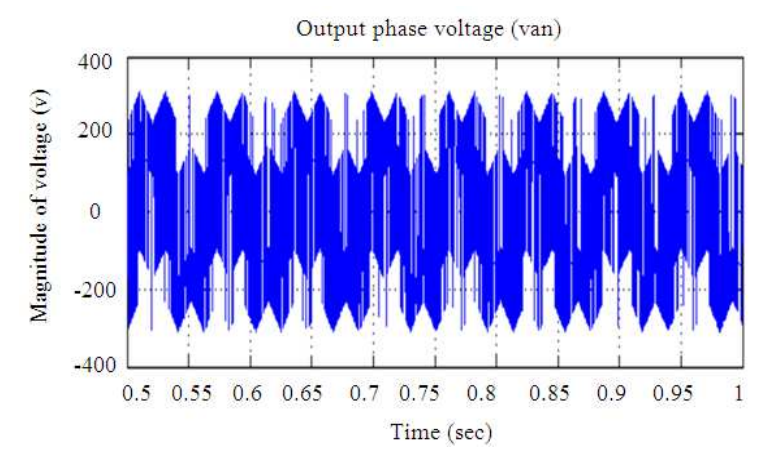

Fig. 6: Phase voltage $\left(\mathrm{v}_{\text {an }}\right)$

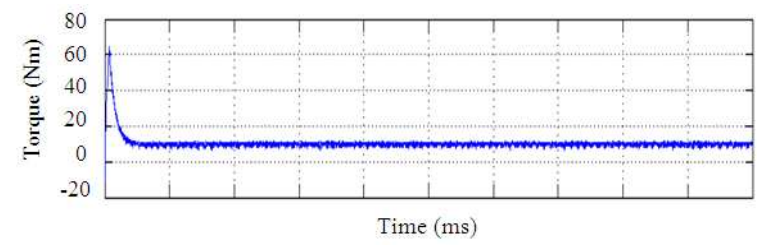

(a)

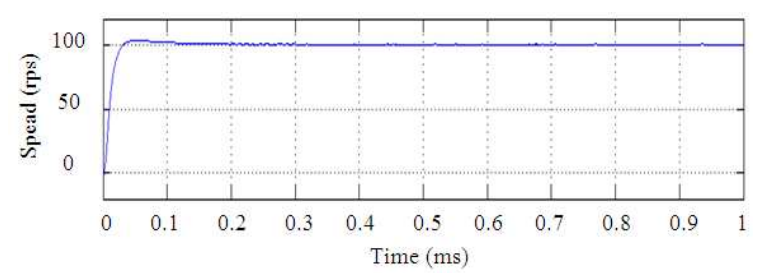

(b)

Fig. 7: Torque and speed-moment of inertia $0.013 \mathrm{~kg}-$ $\mathrm{m}^{2}$

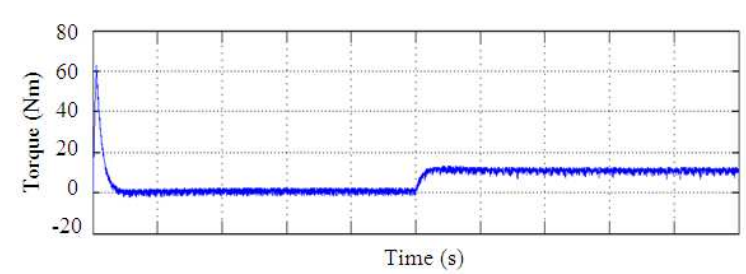

(a)

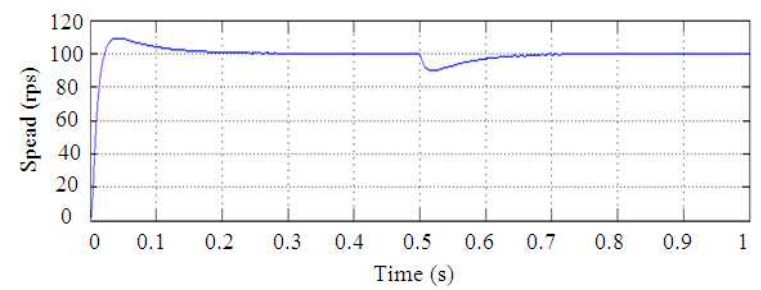

(b)

Fig. 8: Torque and speed-moment of inertia $0.013 \mathrm{~kg}-$ $\mathrm{m}^{2}$ for step time $0.5 \mathrm{sec}$

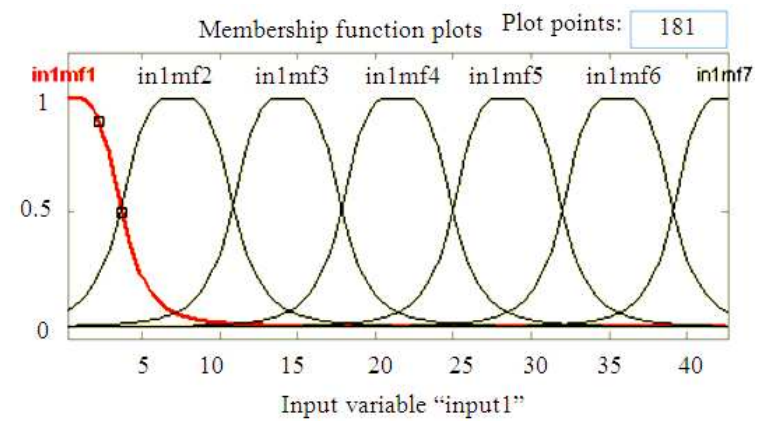

Fig. 9: Membership functions of Speed Error after training

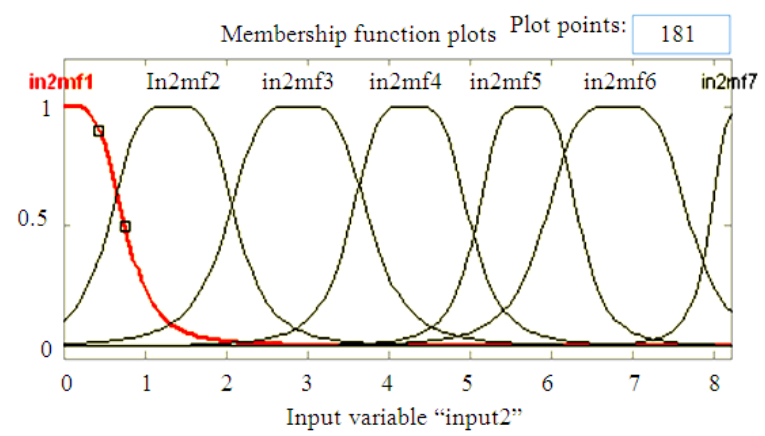

Fig. 10: Membership functions of change in speed error after training

In Fig. 7 shows the torque and speed waveforms for moment of inertia $0.013 \mathrm{~kg}-\mathrm{m}^{2}$ it reaches the steady state torque and speed suddenly at time $0.03 \mathrm{sec}$. It is inferred that increasing the moment of inertia then it takes large time to reach steady state.

The speed error and change in speed error obtained using PI controller is fed as the input of layer 1 in ANFIS structure and trained through GUI tool box of ANFIS in MATLAB simulation software. The resultant membership functions for speed error and change in speed error are shown in Fig. 9 and10 respectively.

The complex ANFIS layer obtained from GUI tool box after training the data is shown in Fig.11.

ANFIS uses the neural network's ability to classify data and find patterns. It then develops a fuzzy expert system that is more transparent to the user and also less likely to produce memorization error than a neural network. ANFIS keeps the advantages of a fuzzy expert system, while removing (or at least reducing) the need for an expert. The problem with ANFIS design is that large amounts of training data require developing an accurate system.

Figure 12 shows the rectangular stator current resulted with ANFIS controller while Fig. 13 and 14 show the torque and speed responses. 


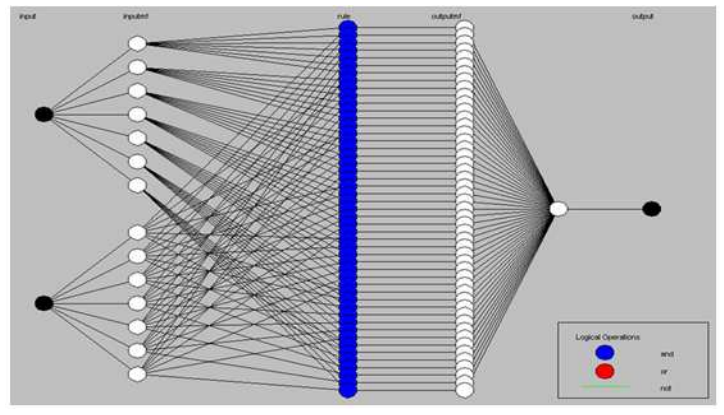

Fig. 11: ANFIS layer obtained
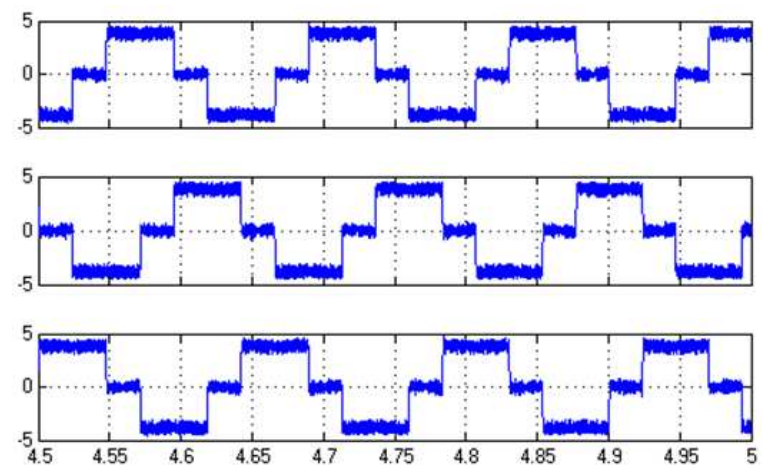

Fig. 12: Stator current-ANFIS controller

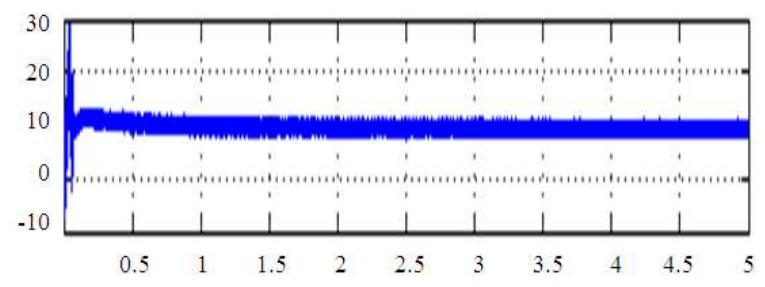

Fig. 13: Torque-ANFIS controller

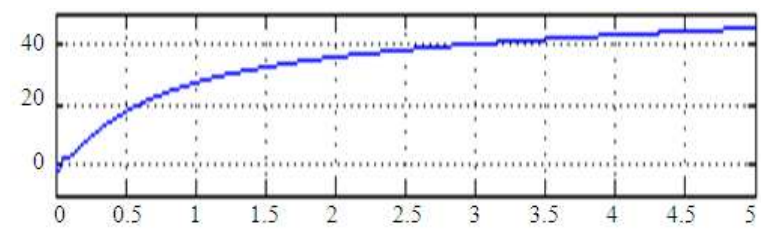

Fig. 14: Speed-ANFIS controller

The speed curve does not show any overshoot and proves the triumph of the designed ANFIS controller. The ANFIS observes the behavior of the drive system and compares the actual performance to a desired reference track. The learning algorithm modifies the ANFIS to more closely match the desired system behavior.

\section{CONCLUSION}

The performance of the developed MATLAB based speed controller of the BLDC drive has been analyzed. The advantages of fuzzy logic and neural network are fused together to form a connectionist adaptive network based fuzzy logic controller. The transient deviation of the response from the set reference following variation in load torque is found to be negligibly small along with a desirable reduction in settling time for the ANFIS controller. Because of high dynamic performance and accurate speed tracking control with good steady-state characteristics, it is proposed for speed control of PMBLDC drives. Firstly, neural network based architecture is described for fuzzy logic control. The specified rules and their membership functions are to be tuned by the back propagation learning algorithm. The performance of the proposed controller is evaluated under various operating condition.

\section{REFERENCES}

Huang, Z.R. and M.N. Uddin, 2006. Development of a simplified Neuro- Fuzzy controller for an IM drive. Proceedings of the IEEE International Conference on Industrial Technology, Dec. 15-17, IEEE Xplore, Mumbai, pp: 63-68. DOI: 10.1109/ICIT.2006.372384

Jadric, M. and B. Terzic, 2001. Design and Implementation of the Extended kalman filter for the speed and rotor position estimation of Brushless motor. Trans. IEEE Indus. Elect., 48: 1065-1073. DOI: $10.1109 / 41.969385$

Kisi, O., 2005. Suspended sediment estimation using neuro-fuzzy and neural network approaches. Hydrol. Sci. J., 50: 683-696. http://direct.bl.uk/bld/PlaceOrder.do?UIN=171344 669\&ETOC $=$ RN\&from $=$ searchengine

Pillay, P. and R. Krishnan, 1989. Modeling, simulation, and analysis of permanent Magnet motor drives. Part II: The brushless de motor drive. IEEE Trans. Ind. Appl., IA-25: 274-279. DOI: 10.1109/28.25542

Radwan, T.S. and M.M. Gouda, 2005. Intelligent speed control of permanent magnet synchronous motor drive based-on neuro-fuzzy approach. Proceedings of the International Conference Power Electronics and Drive Systems (ICPEDS'05), IEEE Xplore, Kuala Lumpur, pp: 602-606. DOI: 10.1109/PEDS.2005.1619757 
Singh, B., B.P. Singh and K. Jain, 2003. Implementation of DSP based "digital speed controller for permanent magnet brushless dc motor. J. Instit. Eng. Ind. Part El Elect. Eng. Div., 16-21.

http://direct.bl.uk/bld/PlaceOrder.do?UIN=137644 937\&ETOC $=$ RN \& from $=$ searchengine

Uddin, M.N., Z.R. Huang and M.M. Chy, 2007. A simplified self-tuned neuro-fuzzy controller based speed control of induction motor drives. Proceedings of the IEEE Power Engineering Society General Meeting, Jun. 24-28, IEEE Xplore, Tampa, FL., pp: 1-8. DOI: 10.1109/PES.2007.385720
Varatharaju, V.M., B.L. Mathur and K. Udhyakumar, 2010. Comprehensive model of a trapezoidal PMBLDC motor and drive system performance with PI speed controller. AMSE Periodicals Model., Measurement Control, 65. http://www.amsemodeling.com/ind2.php?cont $=03$ per \&menu $=/$ menu 3.php\&pag=/datosartic.php\&vis $=1 \&$ editart $=1 \& \mathrm{id}_{-}$ art $=2627$

Vas, P., 1998. Sensorless Vector and Direct Torque Control. 1st Edn., Oxford University Press, USA., ISBN-10: 0198564651, pp: 768. 